\title{
Studies on the Implementation Strategy of English Picture Books for Preschoolers English Learning
}

\author{
Lei LEI \\ College of Foreign Language, Xi'an Shiyou University, Xi'an, Shaanxi, China
}

Keywords: English Picture Books; Preschoolers; Strategy; Reading Methods.

\begin{abstract}
With the development of international exchange of book, preschoolers' English picture books have raised more and more attention of adults. This article will cultivate the preschoolers English reading quality as a perspective, analyze how to improve English ability through reading picture books, use picture books to promote preschool children's English learning interest. The implementation strategy of English picture books reading based on the theory of the Critical Period Hypothesis, the Input Hypothesis of Stephon Krashan and the Output Hypothesis of Merril Swain will be carried out in the article. At last, it explains the importance of reading English picture books, and introduces the implementation strategy and reading methods of English picture books.
\end{abstract}

\section{Introduction}

In recent years, the field of children's books in China has presented an "English picture book fever". The pursuit of picture books by parents and children has made such a new book form that quickly occupies the children's book market. With the English learning craze, children's English picture books have gradually popped up, becoming the first choice for children to learn English.

\section{The Value of English Picture Book for English Learning of Preschooler}

\subsection{It can Stimulate Their Interest in English Learning for the Cognitive and Psychological Characteristics of Learners Who are in the Critical Period of Second Language Acquisition}

Linguist Lenneberg believes that there is a period of time in the process of language acquisition. During this time, language acquisition is the easiest because of the physiological factors. Beyond this period, the language acquisition ability is limited to a certain extent. It is in the critical period of second language acquisition at the age of 3-6, which can also be called the critical period. Children at this age have their own cognitive and psychological developmental characteristics.

With the exchange and development of international books, a large number of excellent English picture books have been introduced into China, and they are increasingly used as auxiliary resources in children English learning.

What is the English picture book?

The picture book was born in Europe in the 17th century. In the 1930s, the mainstream of picture books was directed toward the United States. At the same period, and the picture books entered in a golden age. In the 1950s and 1960s, picture books began to rise in South Korea and Japan. In the 1970s, Taiwan began to read picture books, which led to a wave of reading. [1] Picture books are not only about telling stories, acquiring knowledge, but also helping children to build a spirit and cultivate multiple intelligences. In the 21 st century, picture books have appeared in electronic books. Picture book reading has become the fashion of children's reading around the world.

The composition of English picture books is generally based on pictures. A book tells a simple story supplemented by pictures and English words. The pictures in the book are different in style, some being rich in color and some being exaggerated and abstract. These pictures can bring visual impact to children, stimulate their imagination, and help to cultivate their aesthetic taste and make preliminary understanding of aesthetic perception. Picture books use bright colors and interesting pictures to attract children's attention, and use pictures to describe the stories to help preschoolers understand. The picture book is a reading material designed for children, so it can be children-oriented both in content and form, and can meet the cognitive and psychological 
characteristics of children. Hence, its characteristics are consistent with the cognitive and developmental characteristics of children in the critical period of second language acquisition.

As any language learning cannot be forced, we should ensure that the method of forced-feeding is not used. [2] Because preschoolers are limited by characteristics of their age, their motivation for learning is not obvious. English learning is often based on interest. Therefore, the use of picture books in preschoolers' English teaching is of great help to enhance their interest in language learning.

\subsection{The Language and Literary Forms of English Picture Books can Help Preschoolers Get Effective Language Input and Output}

American linguist Stephon Krashan proposed the Input Hypothesis in the field of second language acquisition. Krashen believes that a large amount of intelligible language input can still activate the language acquisition mechanism inherent in the learner's brain. [3] The language of the English picture book is closely related to children's life, easy to understand and there are a large number of repeated sentence patterns that can attract children's attention. These features of the English picture book ensure that the language input is comprehensible input by the preschoolers.

Merrill Swain in 1985 proposed the Output Hypothesis which is based the deficiencies of the Input Hypothesis. [4] The English picture book is in line with the mode of thinking and expression habits of English-speaking children. Coordinating with the story information contained in the pictures, it can provide a context with real communicative purposes. These linguistic features of English picture books are good for preschoolers to complete the language output.

\section{Problems and Countermeasures in the Implementation of English Picture Book Reading}

\subsection{Adults Select an English Picture Book that does not Meet the English Reading and Cognitive Abilities of Children in Their Corresponding Age}

Selecting a picture book should be student-oriented. Adults must take the characteristics of children into account. As the age of children increasing, the characteristics of them are constantly changing. Therefore, the selection of picture books should be closely followed by the growth of students. Both vocabulary and sentence difficulty are adapted to children of the appropriate age.

For example: The set of picture book The Berenstain Bears is printed in the USA. Its quality is very good, and its language is authentic, but the words and sentences are a bit difficult for children aged 3-6. This set of books is only suitable for children whose vocabularies and sentences have achieved a certain accumulation, it used as a transitional picture book before reading chapter novels.

For zero-based English children, ballad-style picture book is very suitable for them, for example: Eric Carl's "Brown bear, Brown bear, what do you see?" There are animals which children are fond of, as well as a variety of colorful rocks and the repeated rhythm. All of these catch children's attention, appealing preschoolers to listen and slowly sing.

How to select picture books for preschoolers?

In recent years, more and more adults use picture books to train preschoolers to learn English. So how do we choose the right picture book for the age 3-6 children? The content of a good picture book uses pictures to tell stories, and it involves almost all aspects of preschoolers' interest. When we make choices, we need to pay attention to the following four points:

Only can we Understand the Nature and Characteristics of the Reading of Preschoolers' Picture Books, we Choose the Appropriate Content of Picture Books. The early reading of picture books has a great influence on the formation of feelings, character, skills and literacy. A happy and wonderful reading experience is in favor of the formation of early good reading habits, promoting the development of their English language skills. For preschoolers, the purpose of picture book reading is to provide children with reading experience, to develop reading interest and English intimacy, to let children experience the fun of English learning, to encourage children to explore freely, to focus on "a cheerful parent-child interaction", gradually sprouting children's interest in English learning. Therefore, according to the children's interest in the learning stage, 
adults can choose some original English storybooks with interesting content, rich rhythm, simple sentence repetition and visual aesthetic appreciation and organize the reading activities in a planned and step-by-step principle.

In all, when selecting an English picture book, adults should keep to the principle of step by step. The principle of step by step means that the degree of picture book is arranged from easy to difficult, from simple to complex, and gradually deepened and improved. Preschoolers can systematically master the basic knowledge, skills and methods. Adults can allow their children to read simple picture books in English, with the increase in vocabulary, and gradually transferring to the more difficult English picture books.

The Design of the Picture Book should be Interesting. The picture book is mainly about using pictures to tell stories, which can arouse children's interest and enhance children's memories.

For example: The "Town Musicians of Bremen" is a popular fairy tale. The book's painter-color Master Brian believes: "The child's small heart is like a blank book, which is waiting to record love, humor, sympathy and wisdom, and a good picture book can make preschoolers get closer to art and culture." So The Town Musicians of Bremen is full of love and respect, providing preschoolers with a vast space to release their imagination. In the book, flowers, birds, blue sky, grass, forests, and windmills are like a beautiful painting that opens up the space for the children. With a rhythmic language, the children's imagination travels through the story. Therefore, it is easy for preschoolers to remember the key words and sentence patterns inside.

The Combination of Picture Book Reading and New Media. At present, the combination of English picture books and music is very popular among children, and it greatly attracts children's interest and attention.

Take the picture book Silly Sally by Audrey Wood for example, through the style of verses and repeated sentence patterns, this book shows Silly Sally's encounters in the city; with humorous brushwork, and with the lively illustration, it is a good book for both English learning and entertainment functions. Meanwhile, it is easy to download the matching audio of this book from the well-known mobile phone APP: Himalayan FM. In this way, the preschoolers can easily remember the topic sentence: Silly Sally went to town, walking backwards, upside down.

Almost all English original picture books can find matching audio on this software, such as Go Away Mr. Wolf, Five Little Monkeys, and The Wheels on the Bus, etc.

Select an Audio Picture Book and Establish an Auditory Information. Listening is the basic nature of children, and children's books naturally have the need to be converted into audio books. The traditional type of children's books was originally based on paper-based picture books, supplemented by game puzzles, children's English, card charts and so on. In the new media era, first came the audio book with a reading pen. When clicking on a different position on a book, it will make a sound, such as children's picture books and enlightenment books.

In the era of mobile internet, adults scan the QR code to entering into the audio book platform which includes WeChat public account, App and listening website. [5] Through these forms, parents obtain sound resources for children.

An audio picture book refers to a picture book goes with audio on the basis of the illustrations. The audio of the picture book is read aloud, some being rap, and some being presented in the form of story dialogue. Audio picture books have great benefits for English learning, not only attracting children's attention, but also improving their oral ability. The audio picture book adopts English original spoken language, which not only can promote the improvement of preschoolers' hearing, but also standardize their spoken language. For example: In addition to the original story, the most popular audio book of "Little Prince" released 5 songs. The book is welcomed by preschoolers.

\subsection{Improper Reading Methods can Make Children Lose Interest in Picture Books}

Some adults explain the picture book literally, which is just like a simultaneous interpretation. This method will make children feel bored and also underestimate the children's reading ability.

How to apply picture book reading to English learning?

The Combination of English Picture Books and Nursery Rhyme. Initiation stage of learning 
English, learning to sing English nursery rhymes is a very important part of a preschooler English Enlightenment. [6] In addition to stimulate children's interest in English, it cultivates the sense of language and helps improve children's musicianship. The children talked and sang in the beautiful nursery rhymes, bouncing and jumping in the cheerful atmosphere, they learned the English unwittingly. This is the power of interest. Therefore, the most effective way to learn English is to use children's nursery rhymes with English picture books. When singing, the children's attention can be more concentrated on the colorful patterns of the picture books, and these are the best way to help children absorb the outside information.

For example: Mother Goose is a figure in the literature of fairy tales and nursery rhymes. English readers would already have been familiar with the picture book Mother Goose.

Shoo fly, don't bother me,

Shoo fly, don't bother me,

I belong to somebody

The preschoolers learn the basic vocabulary by just singing a few times, and as soon as they see the pattern on the picture book, they can sing immediately, which is of great benefit to foster the standard pronunciation of the children.

The Combination of English Picture Books and the Western Culture. The language of original picture books is more idiomatic English-speaking countries, being in line with the characteristics of children's cognitive. The original picture books related to many Western cultures, customs, thus they open a new window to the world for children. [7] Preschoolers learn about language while learning about history and geography, customs, traditions, lifestyle, literature and art, behavioral norms, values, etc. For example: the picture book The Very Hungry Caterpillar

The entire book runs through the main sentence pattern: One day, the caterpillar ate an apple, but he was very hungry. The language is interesting and catchy, expounding the whole process of caterpillars turning butterflies. And the book is the best material for learning language and scientific knowledge.

In English picture books, preschoolers can learn about important American holidays, such as Halloween, Thanksgiving, Easter, Christmas, etc. They learn about the most popular sports in the English-speaking countries, such as American baseball and English football, understanding Western dining styles and food, such as pasta, steak, pie, cupcakes, desserts, etc.

Maintain the Original Taste of the Picture Book. For the English part of the book, you can follow the book and try to maintain the original taste. [8] The afterwards translation should be natural and colloquial, without being constrained by verbatim translation. In the process of reading a picture book, unless the children ask questions, it is best to keep the rhythm of one English sentence and one Chinese translation. When the preschoolers are familiar with the English picture book, adults just read English.

Because the children are already familiar with the content of the story, the next step is to train them to practice the English "ears". Listening is the foundation of language. When children look at the picture, they will be exposed to words and pictures at the same time. When adults encounter a conversation, he can change the tone slightly, so that the children can make a difference. Don't be too exaggerated to avoid disturbing the children's attention. If preschoolers keep listening to the story, they are standing inside an environment full of English, listening more, they will naturally speak.

During the English picture book reading, adults should encourage children to express their own opinions, give their imagination space and recognition, and help them get spiritual infiltration and spiritual satisfaction in reading, which will help to stimulate their desire for reading. It lays a good start for the realization of long-term reading goals and the improvement of English learning ability.

\section{Conclusion}

Tagore said: "All education begins with our understanding of children's nature." This is especially true in English learning. A good English picture book is the key to opening the door to the English world for children. Reading English picture books should become a habit and a living 
state, so adults must help their children to persevere. [9]

In short, preschoolers are fond of reading the picture books, which is also the way to learn English. As the age increases, the number of words in English stories will also increase, and the types of content should be rich and varied. In addition to cognitive, habitual, and emotional counseling, cultural backgrounds, art and humanities should be added. As long as preschoolers develop an interest, they will take the initiative to explore the world of language, and their learning process being delightful. How to carry out effective English picture book reading, to let the picture book reading play its positive role in English learning, it also requires professionals to constantly research and explore in practice.

At last, Reading brings invaluable spiritual wealth to preschoolers, and builds a free spiritual space and home for them. When children engage in spiritual conversations with those excellent English picture books, they will surely enhance their interest, broaden their horizons, and enrich their hearts.

\section{References}

[1] Lian Rong, Analysis of the Current Situation and Reasons of Preschool Children's English Picture Book Teaching [J]. Journal of Kaifeng Institute of Education, 2018 (8): 230-231

[2] Su Xing, Improve students' reading ability with the original English picture book [J]. English Teachers, Vol.15, No.17.

[3] Cameron, L. Teaching languages to young learners [M]. Cambridge: Cambridge University Press, 2001.

[4] Corbett, Edward P. J. The Little English Handbook Choices \&Conventions [M]. 2nd Ed. New York: John Wiley\& Sons, 1977.

[5] Zhang Yan, Ji Yuan, Research on the Path of Digital Publishing of Children's Books [J]. Social Sciences, 2016 (3).

[6] Wang Jing, Lu Qing, Literature Review of Studies on Children's Picture Books [J]. Journal of Shaanxi Xueqian Normal University, 2017 (12).

[7] Gao Jing, Preschoolers' English Education [H]. East China Normal University Press, 2007

[8] Liu Jia, A New Product in the Era of Picture--A Pure English Picture Book and Its Development [J]. Youth, 2015 (16): 106-107

[9] Kou Jing, Research on the Present Situation of Preschool Children's English Education from the Perspective of Talent Growth [J]. Cai. Shi, 2014 (9). 